\title{
Parenting practices are associated with fruit and vegetable consumption in pre-school children
}

\author{
Teresia M O'Connor ${ }^{1, *}$, Sheryl $\bigcirc$ Hughes $^{1}$, Kathy B Watson ${ }^{1}$, Tom Baranowski ${ }^{1}$, \\ Theresa A Nicklas ${ }^{1}$, Jennie O Fisher ${ }^{2}$, Alicia Beltran ${ }^{1}$, Janice C Baranowski ${ }^{1}$, \\ Haiyan $\mathrm{Qu}^{3}$ and Richard M Shewchuk ${ }^{3}$ \\ 'USDA/ARS Children's Nutrition Research Center, Department of Pediatrics, Baylor College of Medicine, \\ 1100 Bates Street, Houston, TX 77030, USA: ${ }^{2}$ Center for Obesity Research and Education, Department of \\ Public Health, Temple University, Philadelphia, PA, USA: ${ }^{3}$ Department of Health Services Administration, \\ University of Alabama at Birmingham, Birmingham, AL, USA
}

Submitted 11 March 2008: Accepted 10 March 2009: First published online 3 June 2009

\begin{abstract}
Objective: Parents may influence children's fruit and vegetable (F\&V) consumption in many ways, but research has focused primarily on counterproductive parenting practices, such as restriction and pressure to eat. The present study aimed to assess the association of diverse parenting practices to promote $\mathrm{F} \& \mathrm{~V}$ and its consumption among pre-school children.

Design: An exploratory analysis was performed on cross-sectional data from 755 Head Start pre-school children and their parents collected in 2004-5. Data included parent practices to facilitate child F\&V consumption (grouped into five categories); parent-reported dietary intake of their child over $3 \mathrm{~d}$; and a number of potential correlates. $K$-means cluster analysis assigned parents to groups with similar use of the food parenting practice categories. Stepwise linear regression analyses investigated the association of parent clusters with children's consumption of $\mathrm{F} \& \mathrm{~V}$, after controlling for potential confounding factors.

Results: A three-cluster solution provided the best fit $\left(R^{2}=0 \cdot 62\right)$, with substantial differences in the use of parenting practices. The clusters were labelled Indiscriminate Food Parenting, Non-directive Food Parenting and Low-involved Food Parenting. Non-directive parents extensively used enhanced availability and teachable moments' practices, but less firm discipline practices than the other clusters, and were significantly associated with child F\&V intake (standardized $\beta=0 \cdot 09, \quad P<0 \cdot 1$; final model $R^{2}=0 \cdot 17$ ) after controlling for confounders, including parental feeding styles.

Conclusions: Parents use a variety of parenting practices, beyond pressuring to eat and restrictive practices, to promote $F \& V$ intake in their young child. Evaluating the use of combinations of practices may provide a better understanding of parental influences on children's F\&V intake.
\end{abstract}

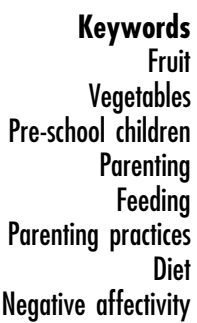

High fruit and vegetable (F\&V) consumption has been associated with a lower prevalence of obesity, type 2 diabetes and CHD in adults ${ }^{(1)}$. In children, higher vegetable $^{(2)}$ and F\&V consumption ${ }^{(3)}$ were associated with lower BMI. However, most US children and adults are

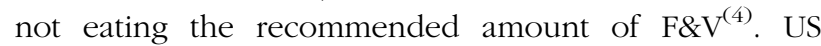
pre-school children consumed approximately $80 \%$ of the recommended daily fruit servings, but only $25 \%$ of the recommended daily vegetable servings ${ }^{(5)}$. Identifying strategies to promote $\mathrm{F} \& \mathrm{~V}$ consumption in young children is critical to promoting healthy nutrition and potentially lowering their risk of obesity and chronic diseases.
Parents likely influence children's behaviour, including F\&V consumption, in many ways. General parenting style has been defined as parents' attitudes about childrearing combined with the emotional climate created by the parents through which parental practices are expressed $^{(6)}$. Parenting style specific to the feeding context has been termed 'feeding style ${ }^{(7)}$. Both general parenting style and its derivative, parental feeding style, have been related to children's $F \& V$ consumption ${ }^{(7-9)}$ and weight status $^{(10)}$. For example, pre-school children whose parents used an authoritative feeding style consumed more vegetables than children whose parents used an authoritarian feeding style ${ }^{(9)}$. 
Parenting style has been differentiated from parenting practices, which are defined as specific parental actions or behaviours designed to influence children's behaviour $^{(6)}$. Since it may be difficult to change parenting or feeding styles, targeting food parenting practices may offer more promise for future obesity prevention programmes. However, most of this literature has been crosssectional and focused on counterproductive parental feeding practices; for example, parental control and pressure to eat were both negatively associated with children's F\&V consumption ${ }^{(11,12)}$. Greater understanding of food parenting practices that promote F\&V consumption is needed. In addition, parents likely do not use only one type of food parenting practice when trying to influence their children's intake. Therefore it is important to investigate how different types of parenting practices work in combination in promoting $\mathrm{F} \& \mathrm{~V}$ consumption in young children.

Previous research on food parenting ${ }^{(13-15)}$ and feeding styles ${ }^{(7-9)}$ has utilized primarily an etic research method. The etic and emic approaches to research have been described in anthropology and psychology, and refer to the perspective taken to better understand cultures or behaviours $^{(16-18)}$. An etic approach relies upon an outsider's perspective and in food-related parenting would be exemplified by having the investigator impose theoryor expert-based constructs to characterize and categorize feeding styles and food parenting practices. Alternatively, an emic approach ${ }^{(16-18)}$ studies groups from within and allows the subjects (or insiders) to describe these phenomena from their own point of view. In food-related parenting, an emic approach would therefore involve parents self-identifying and categorizing parenting practices for promoting $\mathrm{F} \& \mathrm{~V}$ intake in their pre-school children. The present study used an emic approach to: (i) cluster parents based on similarities of their reported use of feeding practices; (ii) describe the clusters based on parent and child characteristics; and (iii) relate children's F\&V consumption with parent cluster membership.

\section{Methods}

\section{Design}

An exploratory secondary analysis was performed on cross-sectional data, originally designed to investigate facilitators and barriers to F\&V consumption among preschool children attending Head Start centres in Houston, Texas and northern Alabama ${ }^{(19)}$. The study was reviewed and approved by the Institutional Review Boards at Baylor College of Medicine and the University of Alabama at Birmingham. Participants were recruited at Head Start centres before and after school in 2004-5. Staff members explained the purpose of the study, confidentiality was assured, and informed consent was obtained. The original study was conducted in two phases. During Phase I, parents participated in eight focus groups with eight to ten parents per group using the nominal group technique $(\mathrm{NGT})^{(20)}$ to identify behaviours parents used (parenting practices) to promote healthy eating such as F\&V consumption in their 3- to 5-year-old children. NGT is a structured focus group method that uses a round-robin approach to give each member equal chance of participation to contribute potential $F \& V$ parenting practices. Participants were then asked to nominate the three parenting practices that were most successful for them in getting their child to eat healthily, in order to provide a rank-ordered list per meeting. An additional NGT was conducted with nine experts in the field to supplement the previously identified practices. After considering the substantive similarities among the items generated across meetings, a final list of thirty-three F\&V-focused practices was identified, five which were provided only by the experts (items 2, 6, 10, 16 and 20). In Phase II a second sample of parents ( $n$ 761) completed a cross-sectional assessment, including a card sort to judge the similarity and distinctions among the thirty-three F\&V parenting practices. Parents were instructed to group the parenting practices into two to ten piles, according to how alike they seemed. Following the card sorts, the parents were interviewed and asked if they used each of the thirtythree $\mathrm{F} \& \mathrm{~V}$ parenting practices, using a dichotomous response (used/not used) for each practice. Parents were also asked to complete a demographic survey and a set of questionnaires described below. The current analysis uses Phase II data.

\section{Antbropometric measures}

Parents' and children's height and weight were obtained by trained staff following structured procedures ${ }^{(21)}$. Height and weight measures for the children were converted to age- and gender-specific BMI $Z$-scores using the revised 2000 growth charts from the Centers for Disease Control and Prevention ${ }^{(22)}$. Parents' height and weight were used to calculate BMI as (weight in $\mathrm{kg}$ )/(height in $\mathrm{m})^{2}$.

\section{Parent and child's fruit and vegetable consumption}

Parents' and children's dietary consumption was assessed by parent report using dietary recalls on three nonconsecutive days (two weekdays and one weekend day). Parents were interviewed in-person or over the telephone by a trained dietitian using the US Department of Agriculture multiple-pass protocol, and were asked to report all food and beverages consumed in the past $24 \mathrm{~h}$ and what their child consumed while with the parent (excluding food consumed while away from the parent such as while at Head Start, since the parents could not report this accurately) ${ }^{(23)}$. The family was provided with two-dimensional food models to be used in the telephone interviews. Dietary data were collected and analysed 
using the Nutrient Data System, University of Minnesota $^{(24)}$. Child F\&V intake was operationalized as the average servings of $F \& V$ consumed by the child after 15.00 hours over $3 \mathrm{~d}$, excluding fried vegetables (such as fried potatoes) and fruit juices. Parent F\&V intake was operationalized as the average servings of F\&V consumed in a $24 \mathrm{~h}$ period over $3 \mathrm{~d}$, excluding fried vegetables and fruit juices. F\&V servings were analysed as a combined variable since the formative work identifying the parenting practices addressed them together. While partial day recalls do not fully reflect the child's daily dietary intake, they do reflect the child's intake that parents could directly influence. The reliability intra-class correlation coefficient across the three days of F\&V consumption was 0.49 (95\% CI $0.43,0.56)$ for children and 0.57 (95\% CI $0 \cdot 51,0 \cdot 62$ ) for parents.

\section{Questionnaire measures}

Caregiver's Feeding Styles Questionnaire

It is important to differentiate the effect of specific parenting practices from parental feeding styles. The Caregiver's Feeding Styles Questionnaire (CFSQ) was developed to measure general feeding styles in lowincome parents of pre-school children ${ }^{(7)}$, consistent with a developmental parenting paradigm ${ }^{(25)}$. The CFSQ includes two sub-scales: a Demandingness sub-scale of nineteen items and a Responsiveness sub-scale, calculated as a ratio of seven child-centred items relative to the mean of the total items ${ }^{(7)}$. A cross-classification of high and low scores based on median splits on the two subscales identified the four feeding styles: (i) Authoritative (high on both); (ii) Authoritarian (high demandingness, low responsiveness); (iii) Indulgent (low demandingness, high responsiveness); and (iv) Uninvolved (low on both). Confirmatory factor analyses supported the factorial integrity of this measure ${ }^{(26)}$. Coefficient $\alpha$ values for parentcentred and child-centred feeding were 0.86 and 0.71 in a previous Head Start sample ${ }^{(7)}$ and 0.83 and 0.67 in the present sample.

\section{Children's Behaviour Questionnaire}

Child temperament has been associated with the weight status of young children ${ }^{(27,28)}$ as well as picky eating in pre-school children ${ }^{(29)}$, and could be a confounding variable. Therefore child temperament was measured by the Children's Behaviour Questionnaire (CBQ), Very Short Form. It assesses child temperament, defined as constitutionally based, individual differences in reactivity and self-regulation ${ }^{(30)}$. The three CBQ sub-scales (Negative Affectivity, Effortful Control and Extraversion/ Surgency) showed adequate internal consistency, with previously reported $\alpha$ values ranging from 0.66 to 0.70 for negative affectivity, from 0.62 to 0.78 for effortful control and from $0 \cdot 70$ to $0 \cdot 76$ for extraversion/surgency ${ }^{(31)}$. The factor structure was invariant across age groups and cul- tures. Convergent validity included parental agreement and prediction of social and laboratory behaviour patterns ${ }^{(30)}$. Values of $\alpha$ in the current sample were 0.65 for negative affectivity, 0.74 for effortful control and 0.63 for extraversion/surgency.

\section{Home fruit and vegetable availability questionnaire}

Home availability of F\&V has been shown to be a strong predictor of $\mathrm{F} \& \mathrm{~V}$ consumption in school-aged children and adolescents ${ }^{(32-34)}$ and therefore a potential confounder in the present analysis. Home availability of F\&V was assessed by a questionnaire with seventeen fruit and eighteen vegetable items. Previous studies reported $\alpha$ of 0.77 among parents of African-American girls ${ }^{(35)}$ and validation with home-inventory checks with parents of 4 th and 6th graders ${ }^{(36)}$. To maintain consistency between measured consumption and availability, high-fat vegetables were not included in the analysis resulting in a thirty-one-item F\&V availability scale. The value of $\alpha$ in the current study sample was $0 \cdot 79$.

\section{Marlow-Crowne social desirability scale, short version} A short form (ten items) of the Marlow-Crowne Social Desirability Scale ${ }^{(37)}$ was used to measure and account for participating parents' response bias towards socially desirable replies. The original research obtained factor loadings ranging from $0 \cdot 28$ to 0.54 with reliability coefficients of 0.49 to 0.75 in four separate populations ${ }^{(37)}$. Internal consistency of the scale in the present study sample was $0 \cdot 44$.

\section{Food parenting practice categories}

Thirty-three parenting practices were grouped using a systematic cognitive mapping approach that involved a card sort, multidimensional scaling and hierarchical cluster analysis procedures, which have been used in previous studies ${ }^{(38-41)}$. Five parent-derived practice (PP) categories were generated: teachable moments (five items), practical methods (nine items), firm discipline (four items), restriction of junk foods (five items) and enhanced availability and accessibility (ten items; Table 1). Internal consistencies of PP category items varied from $0 \cdot 41$ to $0 \cdot 58$.

\section{Statistical analysis}

Parents were clustered based on similar use of PP categories to create profiles of how parents used these practices in combination. Standardized PP category scores were subjected to a $K$-means cluster analysis to identify groups (clusters) of parents who used similar practices based on the PP category scores. $K$-means clustering minimizes the sum of squared distances between a cluster centre and all the points within the cluster. The model $R^{2}$ value and the relevance of the clusters ${ }^{(42)}$ were used to determine the optimal number of clusters. Clusters were 
Table 1 Parent-generated feeding practice categories with proportion of reported use: Head Start pre-school children and their parents in Houston, Texas and northern Alabama, 2004-5

\begin{tabular}{|c|c|c|c|}
\hline Parent practice category & Item & Parent practice & Proportion used \\
\hline \multirow[t]{5}{*}{ Teachable moments } & 4. & To tell your child the eating F\&V will make them strong and healthy & 0.94 \\
\hline & 10. & To use mealtimes to teach your child about healthy eating & $0 \cdot 74$ \\
\hline & 13. & To ask your child to help you with food preparation & $0 \cdot 73$ \\
\hline & 22. & To tell your child they have to try at least a couple of bites but don't have to eat it all & 0.87 \\
\hline & 30. & To tell your child what will happen to them if they eat too many bad foods & 0.83 \\
\hline \multirow[t]{9}{*}{ Practical methods } & 1. & To play a game with your child to get them to eat F\&V & 0.50 \\
\hline & 7. & To add something to make F\&V taste better & 0.62 \\
\hline & 8. & To praise your child when you see them eat F\&V & 0.92 \\
\hline & 9. & To tell your child that their favourite cartoon characters eat F\&V & 0.50 \\
\hline & 12. & To reward your child with sweets if they eat their fruit or vegetables & 0.55 \\
\hline & 15. & To mix F\&V with other foods your child likes & 0.79 \\
\hline & 19. & To make F\&V fun with shapes & 0.37 \\
\hline & 25. & To give your child the specific fruit or vegetable they like & 0.97 \\
\hline & 33. & $\begin{array}{l}\text { To decide what F\&V will be served and then let your child decide which of those they } \\
\text { would eat }\end{array}$ & 0.66 \\
\hline \multirow[t]{4}{*}{ Firm discipline } & 11. & To make your child feel guilty when they don't eat vegetables & 0.27 \\
\hline & 14. & To insist that your child sit at the table until they eat their F\&V & 0.65 \\
\hline & 21. & To keep your child from going to play if they don't eat their fruit or vegetables & $0 \cdot 39$ \\
\hline & 26. & To keep your child from having sweets if they don't eat their fruit or vegetables & 0.75 \\
\hline \multirow[t]{5}{*}{ Restriction of junk foods } & 5. & To limit non-F\&V snacking between meals & $0 \cdot 76$ \\
\hline & 17. & To set limits on the amount of sweet drinks your child can have & 0.85 \\
\hline & 20. & To ask others to not go against you by giving your child candy or sweets & $0 \cdot 72$ \\
\hline & 27. & To keep junk foods out of the house & 0.43 \\
\hline & 29. & To cut back on how often your child eats fast food & $0 \cdot 76$ \\
\hline \multirow{10}{*}{$\begin{array}{l}\text { Enhanced availability/ } \\
\text { accessibility }\end{array}$} & 2. & To schedule meals that include F\&V at the same times every day & 0.59 \\
\hline & 3. & To show your child that you enjoy eating F\&V & 0.93 \\
\hline & 6. & To place F\&V where your child can easily reach them & 0.94 \\
\hline & 16. & To offer F\&V without forcing your child to eat them & 0.91 \\
\hline & 18. & To speak to your child with love so that they will eat F\&V & 0.93 \\
\hline & 23. & To use F\&V for snacks instead of things like cookies and chips & $0 \cdot 87$ \\
\hline & 24. & To include some form of fruit, vegetables or juice in most meals & 0.92 \\
\hline & 28. & To sit at the table and eat F\&V together as a family & 0.94 \\
\hline & 31. & To buy fruit or vegetables instead of junk foods & $0 \cdot 88$ \\
\hline & 32. & To make sure that fruit or vegetables are available around your house & 0.99 \\
\hline
\end{tabular}

F\&V, fruit and vegetables.

labelled to provide meaningful interpretations of their parenting practice profiles.

Tests of independence and ANOVA were used to assess differences among the $K$-means PP clusters by demographic, anthropometric, psychosocial, and F\&V availability and consumption characteristics. Post hoc comparisons for categorical variables were established by conducting additional tests of independence on all possible cluster pairs. Post hoc analyses for ANOVA were conducted using Tukey's HSD (honestly significant difference). The level of significance for post hoc testing was adjusted accordingly. Pearson product moment correlations were used to investigate bivariate relationships among anthropometric, psychosocial, F\&V availability and consumption characteristics of the study sample.

Two sets of stepwise linear regression analyses were used to investigate the association of (i) the individual PP category scores (i.e. teachable moments, practical methods, firm discipline, restriction of junk foods and enhanced availability/accessibility) and (ii) the combination of parenting practices (i.e. the clusters) with children's consumption of $\mathrm{F} \& \mathrm{~V}$, while controlling for potential confounding factors. Statistical significance was set at $P<0 \cdot 10$, given the exploratory nature of these analyses ${ }^{(43)}$.

\section{Results}

Six parents did not complete any portion of the demographic survey or set of questionnaires. The remaining 755 parents provided data for determining PP cluster membership. The rest of the analyses utilized the 662 parent/child dyads that provided complete data. Analyses revealed no significant differences between parents providing complete and incomplete data (Tables 2 and 3). The majority of the parents/guardians were female (95\%); 290 (43.8\%) were African-American, 197 (29.8\%) were Hispanic and $175(26 \cdot 4 \%)$ white. The average child age was $4.5(\mathrm{SD} 0.6)$ years and the average child BMI $Z$-score was $0 \cdot 8(\mathrm{sD} 1 \cdot 5)$. Approximately $60 \%$ of the children were normal weight $(5$ th percentile $\leq \mathrm{BMI}>85$ th percentile for age and gender), 15\% were overweight (85th percentile $\leq$ BMI $>95$ th percentile for age and gender) and $25 \%$ were obese $(\mathrm{BMI} \geq 95$ th percentile for age and gender) $^{(44)}$.

\section{Identification of parent practice clusters}

The model $R^{2}$ values for the $K$-means cluster analysis were $0.48,0.62$ and 0.69 for the two-, three- and four-cluster 
Table 2 Demographic characteristics and parental feeding styles by parenting practices cluster: Head Start pre-school children and their parents in Houston, Texas and northern Alabama, 2004-5

\begin{tabular}{|c|c|c|c|c|c|c|c|c|c|c|}
\hline \multirow[b]{3}{*}{ Characteristic } & \multicolumn{6}{|c|}{ Parenting practices cluster } & & & & \\
\hline & \multicolumn{2}{|c|}{ Low-involved Food Parenting ( $n$ 115) } & \multicolumn{2}{|c|}{ Non-directive Food Parenting ( $n$ 261) } & \multicolumn{2}{|c|}{ Indiscriminate Food Parenting ( $n$ 286) } & \multicolumn{2}{|c|}{ Total (included) ( $n$ 662) } & \multicolumn{2}{|c|}{ Excluded ( $n$ 93) } \\
\hline & $n$ & $\%$ & $n$ & $\%$ & $n$ & $\%$ & $n$ & $\%$ & $n$ & $\%$ \\
\hline \multicolumn{11}{|l|}{ Race/ethnicity +} \\
\hline African-American & 56 & $48 \cdot 7$ & 98 & $37 \cdot 5$ & 136 & $47 \cdot 6$ & 290 & $43 \cdot 8$ & 41 & $44 \cdot 1$ \\
\hline Hispanic-American & 41 & $35 \cdot 7$ & 83 & $31 \cdot 8$ & 73 & $25 \cdot 5$ & 197 & $29 \cdot 8$ & 26 & $28 \cdot 0$ \\
\hline Caucasian-American & 18 & $15 \cdot 7$ & 80 & $30 \cdot 7$ & 77 & $26 \cdot 9$ & 175 & $26 \cdot 4$ & 26 & $28 \cdot 0$ \\
\hline \multicolumn{11}{|l|}{ Parent education level } \\
\hline$<$ High school education & 36 & $31 \cdot 3$ & 62 & $23 \cdot 8$ & 73 & $25 \cdot 5$ & 171 & $25 \cdot 8$ & 15 & $16 \cdot 1$ \\
\hline High school education & 33 & $28 \cdot 7$ & 88 & $33 \cdot 7$ & 102 & $35 \cdot 7$ & 223 & $33 \cdot 7$ & 19 & $20 \cdot 4$ \\
\hline$>$ High school education & 46 & $40 \cdot 0$ & 111 & $42 \cdot 5$ & 111 & $38 \cdot 8$ & 268 & $40 \cdot 5$ & 36 & $38 \cdot 7$ \\
\hline Missing & 0 & $0 \cdot 0$ & 0 & $0 \cdot 0$ & 0 & 0.0 & 0 & 0.0 & 23 & $24 \cdot 7$ \\
\hline \multicolumn{11}{|l|}{ Child's gender } \\
\hline Male & 59 & $51 \cdot 3$ & 134 & $51 \cdot 3$ & 148 & $51 \cdot 7$ & 341 & $51 \cdot 5$ & 43 & $46 \cdot 2$ \\
\hline Female & 56 & $48 \cdot 7$ & 127 & $48 \cdot 7$ & 138 & $48 \cdot 3$ & 321 & $48 \cdot 5$ & 36 & $38 \cdot 7$ \\
\hline Missing & 0 & $0 \cdot 0$ & 0 & 0.0 & 0 & 0.0 & 0 & 0.0 & 14 & $15 \cdot 1$ \\
\hline \multicolumn{11}{|l|}{ Feeding styleł } \\
\hline Authoritative & 6 & $5 \cdot 2$ & 36 & $13 \cdot 8$ & 66 & $23 \cdot 1$ & 108 & $16 \cdot 3$ & 10 & $10 \cdot 8$ \\
\hline Authoritarian & 34 & $29 \cdot 6$ & 52 & $19 \cdot 9$ & 116 & $40 \cdot 6$ & 202 & $30 \cdot 5$ & 17 & $18 \cdot 3$ \\
\hline Indulgent & 34 & $29 \cdot 6$ & 125 & $47 \cdot 9$ & 64 & $22 \cdot 4$ & 223 & $33 \cdot 7$ & 17 & $18 \cdot 3$ \\
\hline Uninvolved & 41 & $35 \cdot 7$ & 48 & $18 \cdot 4$ & 40 & $14 \cdot 0$ & 129 & $19 \cdot 5$ & 12 & $12 \cdot 9$ \\
\hline Missing & 0 & $0 \cdot 0$ & 0 & 0.0 & 0 & $0 \cdot 0$ & 0 & $0 \cdot 0$ & 37 & $39 \cdot 8$ \\
\hline
\end{tabular}

F\&V, fruit and vegetables.

Note: No significant differences between Total (included) and Excluded; missing category not included in analyses.

Significant association $\left(\chi^{2}(4)=14 \cdot 15, P=0 \cdot 007\right)$ between cluster and race/ethnicity. Follow-up $\chi^{2}$ tests of independence by cluster pairs yielded significant $(P<0 \cdot 0167)$ differences between the distributions of the Low-Involved Food Parenting cluster and the Non-directive Food Parenting cluster.

†Significant association $\left(\chi^{2}(6)=83.90, P<0.001\right)$ between cluster and feeding style. Post hoc $\chi^{2}$ tests of independence by cluster pairs yielded significant $(P<0.0167)$ differences between the distributions for all pairwise comparisons. 
models, respectively (data not shown). Although the fourcluster model showed slight improvement in variation, given the marginal improvement in model fit of the fourcluster model coupled with the finding that one cluster accounted for less than $10 \%$ of the parents, the threecluster model was deemed to exhibit the best fit. Post hoc analyses demonstrated that use of the feeding practices was significantly different for the three PP clusters of parents (Fig. 1). At the extremes, parents in cluster 1 (Low-involved Food Parenting) reported low use of all practices intended to promote $\mathrm{F} \& \mathrm{~V}$ intake (range 42-70\%), while parents in cluster 3 (Indiscriminate Food Parenting) reported using at least $75 \%$ of practices in each PP category. A high proportion of cluster 2 (Non-directive Food Parenting) parents reported the use of enhanced availability and teachable moments to promote $\mathrm{F} \& \mathrm{~V}$ intake in their children ( $92 \%$ and $84 \%$, respectively), but reported lower use of practices in the firm discipline category (30\%).

\section{Correlates of the parent practice clusters}

The three parenting clusters revealed significant differences by ethnicity $\left(\chi^{2}(4)=14 \cdot 15, P=0 \cdot 007\right)$ and feeding styles $\left(\chi^{2}(6)=83 \cdot 90, P<0 \cdot 001\right.$; Table 2$)$. Post hoc analysis demonstrated a significantly different distribution by ethnicity for Low-involved Food Parenting and the Nondirective Food Parenting groups $(P<0 \cdot 0167)$, with proportionally higher representation of African-Americans in the Low-Involved Parenting cluster. Feeding styles were significantly different for all pairwise distributions $(P<0 \cdot 0167)$ with the Low-involved Food Parenting group having the highest representation of uninvolved feeding style (35.7\%); the Non-directive Food Parenting group having the highest representation of indulgent feeding (47.9\%); and the Indiscriminate Food Parenting group having high representation of authoritarian feeding (40.6\%). ANOVA of differences among PP clusters demonstrated significant $(P<0.05)$ global effects for parental age, child age and child BMI $Z$-score (Table 3 ). Post hoc analyses showed that mean parental age of $29 \cdot 6$ (SD 6.4) years and child age of $4.3(\mathrm{SD} 0.7)$ years among the Low-involved Food Parenting cluster were significantly $(P<0 \cdot 0167)$ less than the mean parental age of 32.8 (SD 9.2) years and child age of 4.5 (SD 0.6 ) years among the Indiscriminate Food Parenting cluster. Post hoc testing yielded no pairwise differences in child BMI $Z$-scores. No other significant differences were detected across PP clusters.

\section{Correlations of parent practice categories and parent practice clusters}

Practical methods was the only PP category that was bivariately correlated with child F\&V intake $(r=0 \cdot 08$, $P<0 \cdot 05)$. Other variables that were significantly correlated with child $\mathrm{F} \& \mathrm{~V}$ intake were parent $\mathrm{F} \& \mathrm{~V}$ intake $(r=0 \cdot 50$, $P<0 \cdot 01)$, home availability of $\mathrm{F} \& \mathrm{~V}(r=0 \cdot 20, P<0 \cdot 01)$, 


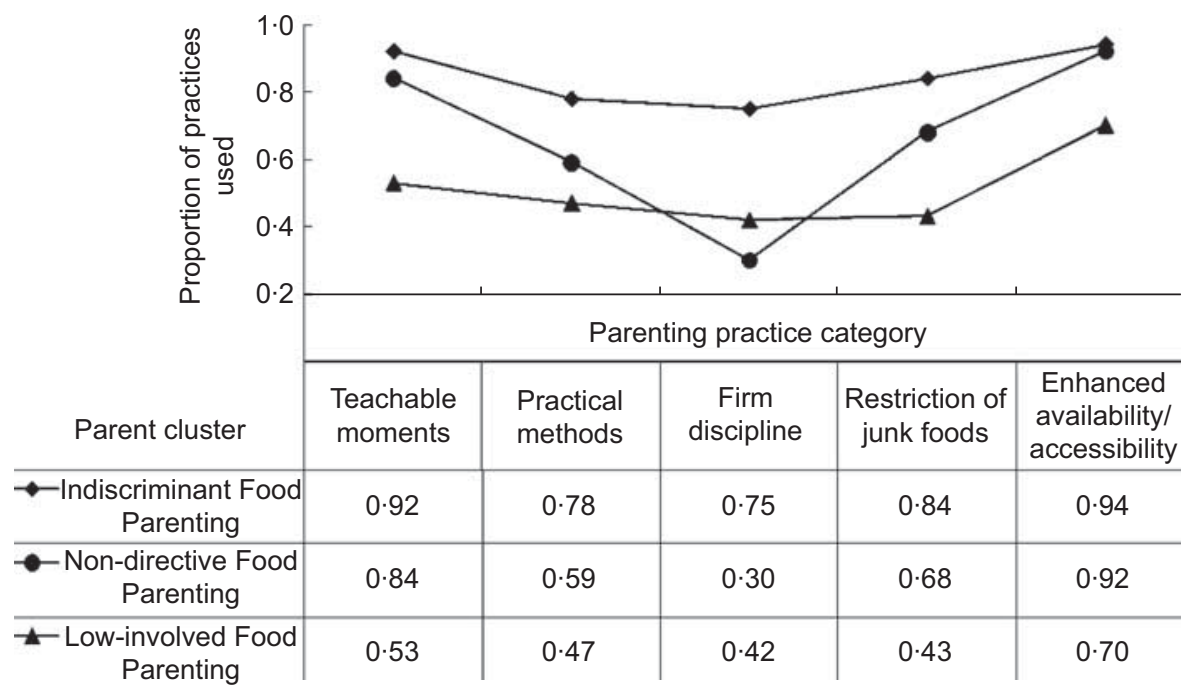

Fig. 1 Reported use (proportion) of each parenting practice category by K-means derived parenting practices cluster: Head Start pre-school children and their parents in Houston, Texas and northern Alabama, 2004-5

child's age $(r=0 \cdot 15, P<0 \cdot 01)$, parent's BMI $(r=-0 \cdot 08$, $P<0 \cdot 05)$ and child's negative affect $(r=-0 \cdot 08, P<0 \cdot 05$; Table 4). All five of the parenting practice categories were significantly inter-correlated, ranging from 0.12 to 0.45 (Table 4), suggesting that parents did not use practices in isolation but rather in combination.

\section{Association of parent practice categories and clusters with child's fruit and vegetable consumption}

Stepwise linear regression analysis with the child's home F\&V consumption as the dependent variable and the PP categories as the independent variable, while accounting for potential confounders, resulted in a final model with $R^{2}$ of $0 \cdot 17$ (data not shown). None of the five PP categories was significantly associated with the child's F\&V consumption. Analysis with PP clusters replacing PP category scores in block 4 resulted in a final model with $R^{2}$ of $0 \cdot 17$ (Table 5 ). Prior to controlling for feeding style (block 4), both the Non-directive (standardized $\beta=0 \cdot 09$, $P<0 \cdot 1)$ and the Indiscriminate Food Parenting clusters (standardized $\beta=0 \cdot 09, P<0 \cdot 1$ ) were associated with children's F\&V intake. When adding the feeding style to the model (block 5), the Non-directive Food Parenting cluster (standardized $\beta=0 \cdot 09, P<0 \cdot 1$ ) continued to be significantly associated with child F\&V consumption. When the parent's F\&V intake was included in block 1 of the stepwise regression model presented in Table 5 (data not shown), there was no longer a significant relationship between the parent clusters and child F\&V intake.

\section{Discussion}

To our knowledge, the present study is the first to use an emic approach to understand low-income parents' perspective of how they try to get their pre-school children to consume F\&V and how their own food parenting behaviours relate to one another. This approach included: (i) engaging parents to generate a list of feeding practices they typically used; (ii) asking parents to organize these feeding practices into PP categories; (iii) testing whether parents could be clustered into patterns of use of the parenting categories; and (iv) investigating how these PP categories and clusters were associated with children's $\mathrm{F} \& \mathrm{~V}$ intake. This approach is different from previous feeding practice research, which has focused primarily on understanding the effects of restrictive and controlling practices on F\&V consumption in children ${ }^{(11,12)}$. It is noteworthy that some of the parenting practices which on the surface may appear to be similar were placed in different categories. However, the resulting parenting practice categories represent how parents collectively view the similarities and relationships of these $F \& V$ parenting practices.

There was no significant association of the five PP categories with children's F\&V consumption. Alternatively, when combined into clusters, the Non-directive Food Parenting cluster retained a significant positive association with children's home F\&V consumption (Table 5) even after controlling for various other factors that might influence child F\&V consumption, including parental feeding style. This association was lost if parental $\mathrm{F} \& \mathrm{~V}$ consumption was included in the model. Given that parental and child F\&V intake are likely correlated for several reasons - such as a shared home availability and accessibility of F\&V (typically determined by the parent), parental role-modelling of dietary behaviours, and shared genetic and behavioural-based preferences for $\mathrm{F} \& \mathrm{~V}$ - its role within the framework of $\mathrm{F} \& \mathrm{~V}$ parenting practices may be difficult to interpret. In addition, the parents reported both their own and their child's dietary intake, inducing a likely significant correlation by the common reporting bias/error for the parent and the child's intake. 
Parents in the Non-directive Food Parenting cluster were different from parents in the other two clusters because they tended to use parenting practices in the enhanced availability/accessibility and teachable moments categories more frequently, with lower use of practices in the firm discipline category (Fig. 1). Parenting practices in the firm discipline category rely on controlling practices that are highly directive and external to the child (such as threats, rewards, pressure to eat and restriction) ${ }^{(46)}$. Several of these have been shown to be counterproductive in getting children to eat $F \& V^{(11,12)}$. On the other hand, teachable moments may also be considered a type of control, but is non-directive and allows for child autonomy ${ }^{(46)}$. Parenting practices that increase the home availability of F\&V may be considered a way to structure the feeding environment to maximize the likelihood that children will consume $F \& V^{(45)}$. Home $F \& V$ availability has consistently been shown to be a predictor of F\&V consumption in schoolaged children and adolescents ${ }^{(32-34)}$ and was a predictor of child $\mathrm{F} \& \mathrm{~V}$ intake in our models.

The concept of authoritative food parenting grew from the general parenting style literature. Hughes et al. proposed that warmth, control and structure are dimensions that provide a more comprehensive framework to identify authoritative food parenting practices and investigate parental influences on children's eating behaviours ${ }^{(45)}$. Authoritative food parenting practices likely include those that are warm (nurturing), provide proactive structure for healthy eating, and use more non-directive controlling practices to promote $\mathrm{F} \& \mathrm{~V}$ intake in children. The emic approach used in the current study identified additional F\&V parenting practices and broadens parenting practices to include both positive and negative practices that may fall into these three dimensions. The exploratory analysis found the combination of $F \& V$ parenting practices that provide structure through practices such as enhanced home availability/accessibility and non-directive control through teachable moments with low use of highly controlling directive practices, such as firm discipline, may be a constellation of authoritative practices that promote F\&V consumption in young children. These relationships need to be investigated utilizing etic approaches to further develop the authoritative food parenting framework and validate measures of these three dimensions of warmth, structure and type of control and test them in longitudinal observational and experimental study designs.

The analysis also found ethnicity to be significantly associated with F\&V consumption in children. Hispanic ethnicity was associated with greater F\&V consumption in children in our sample, which supports ethnic differences in F\&V consumption among children ${ }^{(46)}$ and adults ${ }^{(47)}$ identified in other studies. Further research is needed to clarify the role that culture has on children's F\&V consumption.

The strengths of the present research are the large sample from two regions of the country and data that reflect the perspective of the parent in trying to encourage their 
Table 5 Results from stepwise linear regression analysis of demographics characteristics, psychosocial correlates, feeding styles and parent practices clusters on child F\&V intake: Head Start pre-school children and their parents in Houston, Texas and northern Alabama, 2004-5 ( $n$ 662)

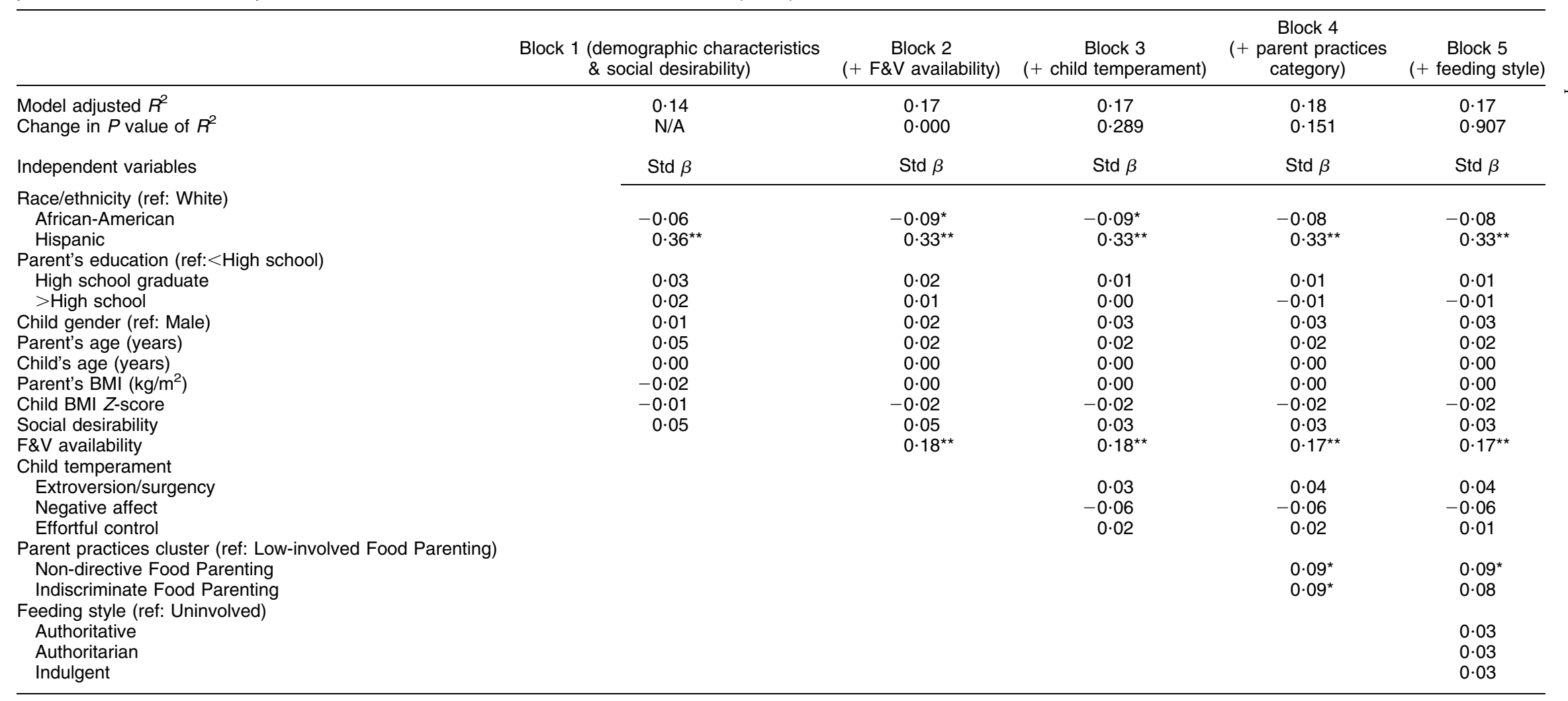

\&V, fruit and vegetables; $\operatorname{Std} \beta$, standardized beta coefficient.

* Significant at $P<0 \cdot 10$ 
child to eat F\&V. In addition, the parent/child dyads who participated in this study were recruited from Head Start centres and represent a low-income sample with high participation of ethnic minorities. Alternatively, several limitations include the generalizability of these results to other populations of families; and all of the behavioural data were based on self-report, which may have reporting biases. A measure was used in order to statistically correct for possible social desirability reporting bias, but it had low internal consistency in our sample. Other research subsequently found problems with brief measures of social desirability ${ }^{(48)}$. Further research will need to assess whether using longer, better measures of social desirability increases correlations of interest. Information about the frequency and consistency of use of these parenting practices were not obtained. Parents who frequently and consistently used these practices likely may have different effects on their child's behaviour than parents who infrequently or inconsistently used these parenting practices.

It will be important to replicate these findings with refined measurement tools in other families with young children of varying socio-economic and ethnicity/racial backgrounds. Preferably, this would be done in a longitudinal sample to assess how the PP categories and PP clusters are related to young children's F\&V consumption over time. Parenting practices that have an effect on the child's immediate consumption of certain foods (such as vegetables) may not be effective or even have the opposite effect in the long term. If these relationships of food parenting clusters to child consumption are replicated in future studies, experimental studies would be warranted to test the effect of training parents to use the authoritative feeding practices, while avoiding the use of others, to facilitate child F\&V consumption.

\section{Conclusions}

The exploratory analyses presented here suggest that evaluating parents' use of combinations of $\mathrm{F} \& \mathrm{~V}$ parenting practices may provide richer understanding of parental influences on children's nutrition behaviours. Further research is needed to verify that using a combination of F\&V parenting practices that provide structure and nondirective control, with avoidance of over-controlling parenting practices, is associated with higher F\&V consumption in children by replicating these findings using more refined measurement techniques in longitudinal samples and in controlled experimental designs.

\section{Acknowledgements}

Sources of funding: The present research was supported by funds from the National Cancer Institute (Grant R01 CA102671). This work is also a publication of the US Department of Agriculture/Agricultural Research Service
(USDA/ARS) Children's Nutrition Research Center, Department of Pediatrics, Baylor College of Medicine (Houston, TX) funded in part by the USDA/ARS (Cooperative Agreement 6250-51000). The contents of this publication do not necessarily reflect the views or policies of the USDA, nor does the mention of trade names, commercial products or organizations imply endorsement from the US government. Conflict of interest declaration: We have no conflict of interest to report. Contribution of authors: R.M.S., T.A.N. and S.O.H. collaborated on the initial grant examining F\&V intake in Head Start children. R.M.S. and H.Q. performed the cognitive mapping of the card sorts to identify the parenting practice categories. K.B.W. performed all other statistical analysis. All authors contributed to the conceptualization and interpretation of the analysis. T.M.O. drafted and coordinated the review of the manuscript. All authors critically reviewed drafts of the manuscript and approved the final version of the manuscript. Acknowledgements: The authors wish to thank Frank Franklin, Professor and Chair, Department of Maternal and Child Health, University of Alabama at Birmingham School of Public Health and the Principal Investigator at the Birmingham site of the larger grant examining F\&V intake in Head Start children; as well as Michelle Feese, the Project Coordinator. The authors also thank the children and parents of Head Start who participated in the study.

\section{References}

1. Bazzano LA, Serdula MK \& Liu S (2003) Dietary intake of fruits and vegetables and risk of cardiovascular disease. Curr Atheroscler Rep 5, 492-499.

2. Cullen KW, Baranowski T, Klesges LM, Watson K, Sherwood NE, Story M, Zakeri I, Leachman-Slawson D \& Pratt C (2004) Anthropometric, parental, and psychosocial correlates of dietary intake of African-American girls. Obes Res 12, Suppl., 20S-31S.

3. Roseman MG, Yeung WK \& Nickelsen J (2007) Examination of weight status and dietary behaviors of middle school students in Kentucky. J Am Diet Assoc 107, 1139-1145.

4. Guenther PM, Dodd KW, Reedy J \& Krebs-Smith SM (2006) Most Americans eat much less than recommended amounts of fruits and vegetables. J Am Diet Assoc 106, 1371-1379.

5. Dennison BA, Rockwell HL \& Baker SL (1998) Fruit and vegetable intake in young children. J Am Coll Nutr 17, 371-378.

6. Darling N \& Steinberg L (1993) Parenting style as context: an integrative model. Psychol Bull 113, 487-496.

7. Hughes SO, Power TG, Orlet Fisher J, Mueller S \& Nicklas TA (2005) Revisiting a neglected construct: parenting styles in a child-feeding context. Appetite 44, 83-92.

8. Kremers SP, Brug J, de Vries H \& Engels RC (2003) Parenting style and adolescent fruit consumption. Appetite 41, 43-50.

9. Patrick H, Nicklas T, Hughes T \& Morales M (2005) The benefit of authoritative feeding style: caregiver feeding styles and children's food consumption. Appetite $\mathbf{4 4}$, 243-249.

10. Rhee K, Appugliese D, Kaciroti N \& Bradley R (2006) Parenting styles and overweight in first grade. Pediatrics 117, 2047-2054. 
11. Fisher JO, Mitchell DC, Smiciklas-Wright H \& Birch LL (2002) Parental influences on young girls' fruit and vegetable, micronutrient, and fat intakes. J Am Diet Assoc 102, 58-64.

12. Wardle J, Carnell S \& Cooke L (2005) Parental control over feeding and children's fruit and vegetable intake: how are they related? I Am Diet Assoc 105, 227-232.

13. Vereecken CA, Keukelier E \& Maes L (2004) Influence of mother's educational level on food parenting practices and food habits of young children. Appetite 43, 93-103.

14. van der Horst K, Kremers S, Ferreira I, Singh A, Oenema A \& Brug J (2007) Perceived parenting style and practices and the consumption of sugar-sweetened beverages by adolescents. Health Educ Res 22, 295-304.

15. Cullen KW, Baranowski T, Rittenberry L, Cosart C, Hebert D \& de Moor C (2001) Child-reported family and peer influences on fruit, juice and vegetable consumption: reliability and validity of measures. Health Educ Res 16, 187-200.

16. Headland T (2008) Chapter 1 Introduction: A dialogue between Kenneth Pike and Marvin Harris on Emics and Etics. In Emics and Etics: The Insider/Outsider Debate. http://www.sil.org/ headlandt/ee-intro.htm (accessed October 2008)

17. Pike KL (1990) On the emics and etics of Pike and Harris. In Emics and Etics: The Insider/Outsider Debate, pp. 28-47. Thousand Oaks, CA: Sage Publications.

18. Morris MW, Leung K, Ames D \& Lickel B (1999) Views from the inside and outside: integrating emic and etic insights about culture and justice judgment. Acad Manag Rev 24, 781-796.

19. Hughes SO \& Shewchuk RM (2006) The differential impact of feeding strategies on children's intake and BMI among a tri-ethnic sample of Head Start families. Poster presented at the Obesity Society's Annual Scientific Meeting. Boston, Massachusetts. Obesity 14, A85.

20. Miller D, Shewchuk R, Elliot TR \& Richards S (2000) Nominal group technique: a process for identifying diabetes self-care issues among patients and caregivers. Diabetes Educ 26, 305-310, 312, 314.

21. Lohman TG, Roche AF \& Martorell M (1988) Anthropometric Standardization Reference Manual. Champaign, IL: Human Kinetics.

22. Kuczmarski R, Ogden C, Guo S, Grummer-Strawn LM, Flegal KM, Mei Z, Wei R, Curtin LR, Roche AF \& Johnson CL (2002) 2000 CDC Growth charts for the United States: methods and development. Vital Health Stat 11 246, 1-190.

23. Baranowski T, Sprague D, Baranowski JH \& Harrison JA (1991) Accuracy of maternal dietary recall for preschool children. I Am Diet Assoc 91, 669-674.

24. Lytle L, Murray D, Perry C \& Eldridge A (1998) Validating fourth-grade students' self-report of dietary intake: results from the 5 a day power plus program. J Am Diet Assoc 98, 570-572.

25. Maccoby E \& Martin J (1983) Socialization in the context of the family: parent-child interaction. In Handbook of Child Psychology, pp. 1-101 [PH Mussen, editor]. New York: Wiley.

26. Hughes SO, Anderson CB, Power TG, Micheli N, Jaramillo S \& Nicklas TA (2006) Measuring feeding in low-income African-American and Hispanic parents. Appetite 46, 215-223.

27. Agras WS, Hammer LD, McNicholas F \& Kraemer HC (2004) Risk factors for childhood overweight: a prospective study from birth to 9.5 years. $J$ Pediatr 145, 20-25.

28. Carey WB, Hegvik RL \& McDevitt SC (1988) Temperamental factors associated with rapid weight gain and obesity in middle childhood. J Dev Behav Pediatr 9, 194-198.

29. Jacobi C, Agras WS, Bryson S \& Hammer LD (2003) Behavioral validation, precursors, and concomitants of picky eating in childhood. J Am Acad Child Adolesc Psychiatry 42, 76-84.
30. Rothbart MK, Ahadi SA, Hershey K \& Fisher P (2001) Investigations of temperament at three to seven years: the Children's Behavior Questionnaire. Child Dev 72, 1394-1408.

31. Putnam SP \& Rothbart MK (2006) Development of short and very short forms of the Children's Behavior Questionnaire. J Pers Assess 87, 102-112.

32. Cullen KW, Baranowski T, Owens E, Marsh T, Rittenberry L \& de Moor C (2003) Availability, accessibility, and preferences for fruit, $100 \%$ fruit juice, and vegetables influence children's dietary behavior. Health Educ Behav 30, 615-626.

33. Neumark-Sztainer D, Wall M, Perry C \& Story M (2003) Correlates of fruit and vegetable intake among adolescents. Findings from Project EAT. Prev Med 37, 198-208.

34. Jago R, Baranowski T \& Baranowski JC (2007) Fruit and vegetable availability: a micro environmental mediating variable? Public Health Nutr 10, 681-689.

35. Cullen KW, Klesges LM, Sherwood NE, Baranowski T, Beech B, Pratt C, Zhou A \& Rochon J (2004) Measurement characteristics of diet-related psychosocial questionnaires among African-American parents and their 8- to 10-yearold daughters: results from the Girls' health Enrichment Multi-site Studies. Prev Med 38, Suppl., S34-S42.

36. Marsh T, Cullen K \& Baranowski T (2003) Validation of a fruit, juice, and vegetable availability questionnaire. J Nutr Educ Behav 35, 93-96.

37. Strahan R \& Gerbasi KC (1972) Short, homogeneous versions of the Marlowe-Crowne Social Desirability Scale. J Clin Psychol 28, 191-193.

38. Shewchuk R \& O'Connor SJ (2002) Using cognitive concept mapping to understand what health care means to the elderly: an illustrative approach for planning and marketing. Health Mark Q 20, 69-88.

39. Shewchuk RM, Franklin FA, Harrington KH, Davies SL \& Windle M (2004) Using cognitive mapping procedures to develop a community-based family intervention. $A m J$ Health Behav 28, 43-53.

40. Shewchuk RM, Rivera PA, Elliott TR \& Adams AM (2004) Using cognitive mapping to understand problems experienced by family caregivers of persons with severe physical disabilities. J Clin Psychol Med Settings 11, 141-150.

41. Shewchuk RM, O'Connor SJ, Williams ES \& Savage GT (2006) Beyond rankings: using cognitive mapping to understand what health care journals represent. Soc Sci Med 62, 1192-1204

42. Koehly L, Arabie P, Bradlow E \& Hutchinson W (2001) How do I choose the optimal number of clusters in cluster analysis? In Methodological and Statistical Concerns of the Experimental Behavioral Researcher [D Iacobucci, editor]. J Consum Psychol 10, 102-104.

43. Baghi H, Noorbaloochi S \& Moore J (2007) Statistical and nonstatistical significance: implications for health care researchers. Qual Manag Health Care 16, 104-112.

44. Barlow SE \& Expert Committee (2007) Expert committee recommendations regarding the prevention, assessment, and treatment of child and adolescent overweight and obesity: summary report. Pediatrics 120, Suppl. 4, S164-S192.

45. Hughes SO, O'Connor TM \& Power TG (2008) Parenting and children's eating patterns: examining control in a broader context. Int J Child Adolesc Health 1, 323-330.

46. Reynolds KD, Baranowski T, Bishop DB, Farris RP, Binkley D, Nicklas TA \& Elmer PJ (1999) Patterns in child and adolescent consumption of fruit and vegetables: effects of gender and ethnicity across four sites. J Am Coll Nutr 18, 248-254.

47. Thompson FE, Midthune D, Subar AF, McNeel T, Berrigan D \& Kipnis V (2005) Dietary intake estimates in the National Health Interview Survey, 2000: methodology, results, and interpretation. J Am Diet Assoc 105, 352-363.

48. Barger S (2002) The Marlowe-Crowne affair: short forms, psychometric structure, and social desirability. J Pers Assess 79, 286-305. 